\title{
Trauma and posttraumatic stress disorder in older adults
}

\author{
Philipp Kuwert MD, Robert H. Pietrzak PhD MPH, Heide Glaesmer PhD
}

\section{Most older adults have been exposed to trauma in their lifetime}

Up to $90 \%$ of older adults have experienced at least one traumatic event in their lifetime, such as military combat, the unexpected death of someone close, serious illness or injury to self or someone close. ${ }^{1,2}$

Traumatic experiences and PTSD are associated with several physical health conditions in older adults

People who have experienced trauma or have PTSD have higher rates of cardiovascular diseases and related risk factors (e.g., hypertension, coronary artery disease, hyperlipidemia), as well as other common medical conditions (e.g., osteoarthritis, diabetes) ${ }^{3.4}$ (Appendix 1, available at www.cmaj.ca/lookup/suppl/doi :10.1503/cmaj.120866/-/DC1).

\section{References}

1. Pietrzak RH, Goldstein RB, Southwick SM, et al. matic stress disorder among older adults in the United States: results from Wave 2 of the National Epidemiologic Survey on Alcohol and Related Conditions. Am J Geriatr Psychiatry 2012;20:380-90.

2. Glaesmer H, Kaiser M, Braehler E, et al. Posttraumatic symptomatology in the elderly and its comorbidity with depression and somatization - a German population based study. Aging Ment Health 2012;16:403-12.

3. Glaesmer H, Brähler E, Gündel H, et al. The association of traumatic experiences and posttraumatic stress disorder with physical morbidity in old age - a German population based study. Psychosom Med 2011; 73:401-6. Psychiatric comorbidity of full and partial posttrau-

\section{Exposure to trauma is associated with posttraumatic stress disorder and several other psychological disorders in older adults}

Population-based studies involving older adults in the United States have found that the lifetime prevalence of full posttraumatic stress disorder (PTSD) ranges from $2.8 \%$ to $4.5 \%$ and that an additional $5.5 \%$ have partial or subsyndromal PTSD. ${ }^{1}$ These conditions, which may persist for more than a decade, often co-occur with mood and anxiety disorders, such as major depression and generalized anxiety disorder. ${ }^{1,2}$ In some countries, traumatic experiences related to war in early life are common and may be associated with elevated PTSD symptoms, even decades later. ${ }^{2}$

\section{Screening instruments are effective in identifying people with symptoms of PTSD}

Available evidence suggests that instruthe Primary Care PTSD Screen are useful in screening for probable PTSD. ${ }^{5}$ The cut-off point that provides optimal sensitivity and specificity on instruments such as the PTSD Checklist may be lower for older adults than for younger people. ${ }^{5}$

4. Pietrzak RH, Goldstein RB, Southwick SM, et al. Physical health conditions associated with full and partial posttraumatic stress disorder among older adults in the United States: results from Wave 2 of the National Epidemiologic Survey on Alcohol and Related Conditions. J Am Geriatr Soc 2012;60:296-303.

5. Cook JM, Elhai JD, Arean PA. Psychometric properties of the PTSD checklist with older primary care patients. J Trauma Stress 2005;18:371-6.

6. Böettche M, Kuwert P, Knaevelsrud C. Posttraumatic stress disorder in older adults: an overview of characteristics and treatment approaches. Int J Geriatr Psychiatry 2012;27:230-9.

7. Chan D, Fan MY, Unützer J. Long-term effectiveness of collaborative depression care in older primary care patients with and without PTSD symptoms. Int J Geriatr Psychiatry 2011;26:758-64. ments such as the PTSD Checklist and

\section{Resources}

- PTSD Checklist: www.ptsd.va.gov/professional/pages/assessments/ptsd-checklist.asp

- Primary Care PTSD Screen: www.ptsd.va.gov/professional/pages/assessments/pc-ptsd.asp
Data regarding PTSD treatments for older adults are lacking

Preliminary empirical data and case studies indicate positive treatment outcomes of psychotherapies, such as cognitive-behavioural therapy and life-review therapy for elderly individuals with PTSD. ${ }^{6}$ Patients with comorbid depression may benefit from a collaborative approach including antidepressant medication.?
Competing interests: Robert Pietrzak has served as a consultant for CogState. None declared for Philipp Kuwert and Heide Glaesmer.

This article has been peer reviewed.

Affiliations: From the Department of Psychiatry and Psychotherapy (Kuwert) at the HELIOS Hansehospital Stralsund, Ernst-Moritz-ArndtUniversity Greifswald, Greifswald, Germany; the National Center for Posttraumatic Stress Disorder, Veterans Affairs Connecticut Healthcare System, and the Department of Psychiatry, Yale University School of Medicine (Pietrzak), New Haven, Conn.; and the Department of Medical Psychology and Medical Sociology (Glaesmer), University of Leipzig, Leipzig, Germany.

Correspondence to: Philipp Kuwert, kuwert@ uni-greifswald.de

CMAJ 2013. DOI:10.1503/cmaj.120866 